Thomas H. Naylor * e Jayme Porto Carreiro Filho **

\title{
Modelos econômicos simulados em computador
}

1. Introduçáo. 2. Um exemplo de simulaçăo do mercado de capitais. 3. Algumas aplicaçóes da simulação.
Entre os métodos de avaliação da eficiência de uma política econômica, destacam-se os seguinies:

a) A realização de experiências controladas efetuadas com um sistema econômico de uma firma, uma indústria ou um país.

No caso de um complexo industrial ou de setores mais amplos, restrições de ordem prática impossibilitam a experiência controlada.

O método pode ser aplicado em casos restritos, como por exemplo, a experimentação de diferentes políticas de propaganda e comercialização. No entanto, mesmo nestes casos, a realização de experiências reais com um sistema econômico conduz a resultados geralmente duvidosos, já que dificilmente tôdas as variáveis exógenas se mantêm constantes.

b) Uma segunda alternativa seria a observação a posteriori. Quando se dispõe de dados a respeito de um sistema econômico durante um certo período de tempo, é possível a análise, a posteriori, das políticas empregadas neste período Suponhamos, por exemplo, que sejam conhecidas as séries temporais de uma variável económica como a renda per capita de cada estado da federação.

Tentando explicar a diversidade de crescimento da renda per capita, entre os diversos estados, pela influência das diferentes políticas econômicas empregadas associadas a uma flutuação aleatória relativamente pequena, seria possivel avaliar os efeitos das políticas utilizadas no crescimento da renda por capita.

Normalmente os dados necessários a êste tipo de análise não são disponiveis ao longo do tempo. Mesmo quando disponíveis, por não serem os dados obtidos a partir de experiência controlada, é altamente discutível a hipótese de que as diferenças entre as variáveis endógenas (dependentes) - no exemplo citado, renda per capita sejam atribuídas principalmente às variáveis controláveis da politica econômica.

Quando a experiência controlada é inviável, cara, ou pouco prática ou, ainda, na carência de dados que permitam análise, a posteriori, resta a alternativa da simulação.

c) O computador digital de alta velocidade permite hoje ao economista e ao administrador realizar experiências controladas semelhantes da experiências de laboratório, há muito empregada pelos químicos, físicos e outros cientistas. A única diferença entre a experiência real e a simulada é que nesta última é utilizado um modêlo matemático do sistema real.

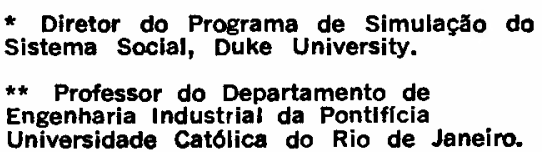
Sistema Social, Duke University.

** Professor do Departamento de Engenharia Industrial da Pontificia Universidade Catolica do Rio de Janeiro. 
Chama-se simulação a técnica de análise numérica, de experimentação sôbre modelos matemáticos.

\section{UM EXEMPLO DE SIMULAÇAO DO MERCADO DE CAPITAIS}

Um investidor deseja avaliar uma determinada estratégia na compra e venda de ações.

Considerando um exemplo simples, suponha-se que 0 investidor negocie apenas com ações da companhia $\mathbf{A}$. Inicialmente, êle possui $10 \mathrm{mil}$ ações cotadas a Cr $\$ 10,00$ cada uma. Como é impossível contato por telefone, tôda manhã o corretor o procura para saber de suas decisões. Dêsse modo, o investidor faz no máximo uma transação por dia, pagando uma comissão de $2 \%$ sôbre o valor da transação, quer seja ela compra ou venda.

\section{A política a ser testada pelo} investidor é a seguinte:

1. Vender tôdas as ações que possua, quando cai o preço.

2. Comprar quando o preço sobe, investindo o máximo. Eventualmente poderá sobrar um residuo em dinheiro, insuficiente para comprar uma ação, por não ser o capital disponível para a compra divisível pelo valor da ação.

Segundo a política apresentada, o investidor com ações não vende, enquanto o preço estiver estável ou em alta, mas no momento em que cal a cotação, êle vende tôdas as ações. Aguarda, sem ordenar nenhuma operação, até o primeiro sinal de alta da ação da companhia A para comprar novamente.

Um modêlo matemático capaz de descrever a posição (capital) do investidor resume-se em :

1. quando vende:

POSICAO $=$ N..$^{\circ}$ ACOESS $x$ $\times$ COTACCAO - COMISSAO + + RESIDUO ANTERIOR

2. quando não há transação:

POSIÇAO = POSIÇAO DIA ANTERIOR

3. quando compra:

POSIÇAO $=$ N. ${ }^{\circ}$ AÇOES $x$

$\times$ COTAÇAO + RESIDUO

Para utilizar êste modêlo, deve-se ainda, de alguma maneira, prever o comportamento futuro do mercado de capitais. A maneira mais simples de descrever a posição do investidor seria aplicar o modêlo mencionado à série histórica das cotações do papel A. Um exemplo dêste comportamento simplista consiste em verificar qual seria a posição do investidor hoje, caso tivesse adotado a política que se quer testar nos últimos 30 dias.
Sofisticando um pouco o modêlo seria exeqüível estimar probabilidades para os possíveis comportamentos do mercado no futuro próximo.

Suponhamos que a Bôlsa de Valôres apresente uma tendência para alta e que projeções do comportamento das ações da companhia A para o próximo mês tenham sido feitas, chegando-se às seguintes estimativas de probabilidade para o comportamento das ações em dia em que haja pregão na Bôlsa.

Comportamento das

ações da companhia

A em dia de pregão

Probabilidade

Estável

Alta de Cr $\$ 1,00$

Alta de Cr $\$ 2,00$

Baixa de Cr\$1,00

Pode-se fàcilmente, com auxílio de um dado, simular seqüências de cotações das ações da companhia A para os próximos dias de atividade do mercado, usando-se o seguinte critério:

Resultado de um lance do dado

Comportamento da ação

Ponto 1

Ponto 2

Ponto 3

Ponto 4

Ponto 5

Ponto 6

Baixa de Cr $\$ 1,00$

Estável

Estável

Estável

Alta de Cr\$ 1,00

Alta de Cr $\$ 2,00$

A seqüência de cotações do quadro 1 foi obtida com a aplicação dêsse critério, a partir da cotação inicial de Cr\$ 10,00 .

QUADRO 1.*

\begin{tabular}{|c|c|c|c|}
\hline $\begin{array}{c}\text { N. }{ }^{\circ} \text { de } \\
\text { ordem } \\
\text { do lance }\end{array}$ & $\begin{array}{c}\text { Ponto } \\
\text { do } \\
\text { dado }\end{array}$ & $\begin{array}{c}\text { Variação } \\
\text { da } \\
\text { cotação }\end{array}$ & Cotação \\
\hline $\begin{array}{l}- \\
1 \\
2 \\
3 \\
4 \\
5 \\
6 \\
7 \\
8 \\
9 \\
10 \\
11 \\
12 \\
13 \\
14 \\
15 \\
16^{* *}\end{array}$ & $\begin{array}{l}-1 \\
1 \\
5 \\
1 \\
6 \\
3 \\
5 \\
1 \\
2 \\
2 \\
5 \\
3 \\
5 \\
1 \\
3 \\
6\end{array}$ & $\begin{array}{r}-1 \\
-1 \\
+1 \\
+1 \\
+1 \\
0 \\
+1 \\
-1 \\
0 \\
0 \\
+1 \\
0 \\
+1 \\
1 \\
1 \\
0 \\
2\end{array}$ & $\begin{array}{r}10,00 \\
9,00 \\
8,00 \\
9,00 \\
8,00 \\
10,00 \\
10,00 \\
11,00 \\
10,00 \\
10,00 \\
10,00 \\
11,00 \\
11,00 \\
12,00 \\
11,00 \\
11,00 \\
13,00\end{array}$ \\
\hline
\end{tabular}

* Na realidade foi usada uma tábua de números aleatórios na determinacão da seqüência dos "pontos" do dado.

** Supõe-se 16 dias de atividade na Bôlsa, em um mês. 


\begin{tabular}{|c|c|c|c|c|c|c|c|}
\hline Dia & Variação & Cotação & Comissão & Açöes & Caixa & Posição & Teate 1 \\
\hline $\begin{array}{r}0 \\
1 \\
2 \\
3 \\
4 \\
5 \\
6 \\
7 \\
8 \\
9 \\
10 \\
11 \\
12 \\
13 \\
14 \\
15 \\
16\end{array}$ & $\begin{array}{r}1.00 \\
-1.00 \\
1.00 \\
-1.00 \\
2.00 \\
0.00 \\
1.00 \\
-1.00 \\
0.00 \\
0.00 \\
1.00 \\
0.00 \\
1.00 \\
1.00 \\
0.00 \\
2.00\end{array}$ & $\begin{array}{r}10.00 \\
9.00 \\
8.00 \\
9.00 \\
8.00 \\
10.00 \\
10.00 \\
11.00 \\
10.00 \\
10.00 \\
10.00 \\
11.00 \\
11.00 \\
12.00 \\
11.00 \\
11.00 \\
13.00\end{array}$ & $\begin{array}{l}1800.00 \\
1729.25 \\
1537.12 \\
1476.80 \\
1476.80 \\
1481.99\end{array}$ & $\begin{array}{r}10000 \\
0 \\
0 \\
9607 \\
0 \\
7384 \\
7384 \\
7384 \\
0 \\
0 \\
0 \\
6450 \\
6450 \\
6450 \\
0 \\
0 \\
5243\end{array}$ & $\begin{array}{r}0.00 \\
882000.00 \\
88200.00 \\
7.74 \\
75326.62 \\
9.81 \\
9.81 \\
9.81 \\
72373.02 \\
72373.02 \\
72373.02 \\
4.01 \\
4.01 \\
4.01 \\
69535.02 \\
69535.02 \\
12.84\end{array}$ & $\begin{array}{r}100000.00 \\
88200.00 \\
88200.00 \\
86470.74 \\
75326.62 \\
73849.82 \\
73849.82 \\
81233.82 \\
72373.02 \\
72373.02 \\
72373.02 \\
70954.02 \\
70954.02 \\
77404.02 \\
69535.02 \\
69535.02 \\
68171.84\end{array}$ & \\
\hline $\begin{array}{r}\text { Dia } \\
0 \\
1 \\
2 \\
3 \\
4 \\
5 \\
6 \\
7 \\
8 \\
9 \\
10 \\
11 \\
12 \\
13 \\
14 \\
15 \\
16\end{array}$ & $\begin{array}{r}0.00 \\
0.00 \\
-1.00 \\
-1.00 \\
0.00 \\
0.00 \\
0.00 \\
2.00 \\
-1.00 \\
2.00 \\
0.00 \\
2.00 \\
2.00 \\
0.00 \\
-1.00 \\
-1.00\end{array}$ & $\begin{array}{r}\text { Cotação } \\
\\
10.00 \\
10.00 \\
10.00 \\
9.00 \\
8.00 \\
8.00 \\
8.00 \\
8.00 \\
10.00 \\
9.00 \\
11.00 \\
11.00 \\
13.00 \\
15.00 \\
15.00 \\
14.00 \\
13.00\end{array}$ & $\begin{array}{l} \\
1800.00 \\
1729.39 \\
1556.46 \\
1495.34\end{array}$ & $\begin{array}{r}\text { Ações } \\
10000 \\
10000 \\
10000 \\
0 \\
0 \\
0 \\
0 \\
0 \\
8647 \\
0 \\
6797 \\
6797 \\
6797 \\
6797 \\
6797 \\
0 \\
0\end{array}$ & $\begin{array}{r}\text { Caixa } \\
0.00 \\
0.00 \\
0.00 \\
88200.00 \\
88200.00 \\
88200.00 \\
88200.00 \\
88200.00 \\
0.60 \\
76267.14 \\
4.80 \\
4.80 \\
4.80 \\
4.80 \\
4.80 \\
93259.64 \\
93259.64\end{array}$ & $\begin{array}{r}\text { Posiçå } \\
\\
100000.00 \\
100000.00 \\
100000.00 \\
88200.00 \\
88200.00 \\
88200.00 \\
88200.00 \\
88200.00 \\
86470.60 \\
76267.14 \\
74771.80 \\
74771.80 \\
88365.80 \\
101959.80 \\
101959.80 \\
93259.64 \\
93259.64\end{array}$ & Teste 2 \\
\hline $\begin{array}{r}\text { Dia } \\
\\
0 \\
1 \\
2 \\
3 \\
4 \\
5 \\
6 \\
7 \\
8 \\
9 \\
10 \\
11 \\
12 \\
13 \\
14 \\
15 \\
16\end{array}$ & $\begin{array}{l}0.00 \\
2.00 \\
0.00 \\
0.00 \\
2.00 \\
0.00 \\
1.00 \\
2.00 \\
0.00 \\
0.00 \\
0.00 \\
2.00 \\
0.00 \\
0.00 \\
2.00 \\
2.00\end{array}$ & $\begin{array}{c}\text { Cotação } \\
10.00 \\
10.00 \\
12.00 \\
12.00 \\
12.00 \\
14.00 \\
14.00 \\
15.00 \\
17.00 \\
17.00 \\
17.00 \\
17.00 \\
19.00 \\
19.00 \\
19.00 \\
21.00 \\
23.00\end{array}$ & Comissão & $\begin{array}{l}\text { Açб̋ss } \\
10000 \\
10000 \\
10000 \\
10000 \\
10000 \\
10000 \\
10000 \\
10000 \\
10000 \\
10000 \\
10000 \\
10000 \\
10000 \\
10000 \\
10000 \\
10000 \\
10000\end{array}$ &  & $\begin{array}{c}\text { Posição } \\
100000.00 \\
100000.00 \\
120000.00 \\
120000.00 \\
120000.00 \\
140000.00 \\
140000.00 \\
150000.00 \\
170000.00 \\
170000.00 \\
170000.00 \\
170000.00 \\
190000.00 \\
190000.00 \\
190000.00 \\
210000.00 \\
230000.00\end{array}$ & Teste 3 \\
\hline Dia & Variação & Cotação & Comissão & Açס̃es & Caixa & Posição & Teste 4 \\
\hline $\begin{array}{r}0 \\
1 \\
2 \\
3 \\
4 \\
5 \\
6 \\
7 \\
8 \\
9 \\
10 \\
11 \\
12 \\
13 \\
14 \\
15 \\
16\end{array}$ & $\begin{array}{r}1.00 \\
0.00 \\
2.00 \\
-1.00 \\
1.00 \\
-1.00 \\
2.00 \\
0.00 \\
0.00 \\
1.00 \\
2.00 \\
0.00 \\
1.00 \\
-1.00 \\
0.00 \\
1.00\end{array}$ & $\begin{array}{r}10.00 \\
9.00 \\
9.00 \\
11.00 \\
10.00 \\
11.00 \\
10.00 \\
12.00 \\
12.00 \\
12.00 \\
13.00 \\
15.00 \\
15.00 \\
14.00 \\
13.00 \\
13.00 \\
14.00\end{array}$ & $\begin{array}{l}1800.00 \\
1729.19 \\
1572.00 \\
1510.51 \\
1373.19 \\
1319.28\end{array}$ & $\begin{array}{r}10000 \\
0 \\
0 \\
7860 \\
0 \\
6866 \\
0 \\
5497 \\
5497 \\
5497 \\
5497 \\
5947 \\
5497 \\
0 \\
0 \\
0 \\
5281\end{array}$ & $\begin{array}{r}0.00 \\
88200.00 \\
88200.00 \\
10.80 \\
77038.80 \\
2.27 \\
67289.08 \\
5.80 \\
5.80 \\
5.80 \\
5.80 \\
5.80 \\
5.80 \\
75424.64 \\
75424.64 \\
75424.64 \\
11.96\end{array}$ & $\begin{array}{r}100000.00 \\
88200.00 \\
88200.00 \\
86470.80 \\
77038.80 \\
75528.28 \\
67289.08 \\
65969.80 \\
65969.80 \\
65969.80 \\
71466.80 \\
82460.80 \\
82460.80 \\
75424.64 \\
75424.64 \\
75424.64 \\
73945.96\end{array}$ & \\
\hline
\end{tabular}




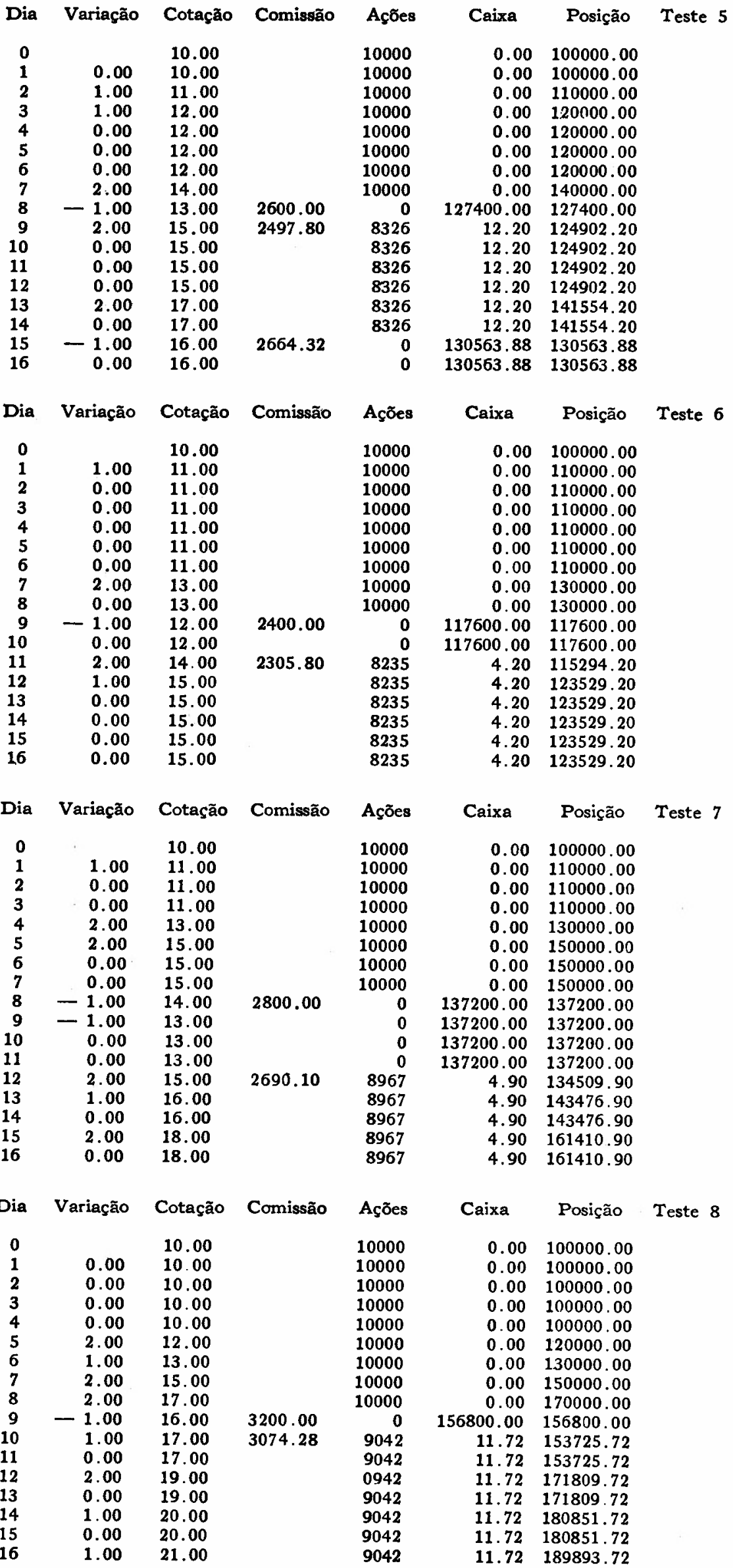




\begin{tabular}{|c|c|c|c|}
\hline Dia & Variação & Cotação & Comissão \\
\hline 0 & & 10.00 & \\
\hline 1 & 2.00 & 12.00 & \\
\hline 2 & 0.00 & 12.00 & \\
\hline 3 & 0.00 & 12.00 & \\
\hline 4 & 2.00 & 14.00 & \\
\hline 5 & 1.00 & 15.00 & \\
\hline 6 & -1.00 & 14.00 & 2800.00 \\
\hline 7 & 2.00 & 16.00 & 2689.92 \\
\hline 8 & -1.00 & 15.00 & 2521.80 \\
\hline 9 & 0.00 & 15.00 & 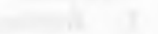 \\
\hline 10 & 0.00 & 15.00 & \\
\hline 11 & 0.00 & 15.00 & \\
\hline 12 & -1.00 & 14.00 & \\
\hline 13 & -1.00 & 13.00 & \\
\hline 14 & 1.00 & 14.00 & 2423.12 \\
\hline 15 & -1.00 & 13.00 & 2250.04 \\
\hline 16 & 0.00 & 13.00 & \\
\hline & $\begin{array}{l}\text { QUADRO } 3 \\
\text { qüuência } \\
\text { vestidor }\end{array}$ & $\begin{array}{l}\text { Distribuiç } \\
\text { posiçãa } \\
\text { espondent }\end{array}$ & $\begin{array}{l}\text { ão de } \\
\text { final do } \\
\text { te a } 72\end{array}$ \\
\hline & Class & & Freqüência \\
\hline$(-$ & $\infty$ & $80.000)$ & 6 \\
\hline$[+$ & $80.000+$ & $(00.000)$ & 20 \\
\hline$[\div$ & $110.000+$ & $40.000)$ & 18 \\
\hline$[+$ & $140.000+$ & $(70.000)$ & 14 \\
\hline [t & $170.000+$ & $200.000)$ & 8 \\
\hline & $200.000+$ & $\infty)$ & 6 \\
\hline
\end{tabular}

Pode-se agora determinar qual seria o lucro do investidor neste mês simulado, caso adote a política de compra e venda exposta anteriormente.

Repetindo êste procedimento simulou-se a história da posição do investidor diversas vêzes (ver quadro 2).

\begin{tabular}{|c|c|c|}
\hline Ações & Caixa & Teste 9 \\
\hline 10000 & 0.00 & 100000.00 \\
\hline 10000 & 0.00 & 120000.00 \\
\hline 10000 & 0.00 & 120000.00 \\
\hline 10000 & 0.00 & 120000.00 \\
\hline 10000 & 0.00 & 140000.00 \\
\hline 10000 & 0.00 & 15000.00 \\
\hline 0 & 137200.00 & 137200.00 \\
\hline 8406 & 14.08 & 134510.08 \\
\hline 0 & 123582.28 & 123582.28 \\
\hline 0 & 123582.28 & 123582.28 \\
\hline  & 123682.28 & 123582.28 \\
\hline 0 & 123582.28 & 123582.28 \\
\hline 0 & 123582.28 & 123582.28 \\
\hline 0 & 123582.28 & 123582.28 \\
\hline 8654 & 3.15 & 121759.16 \\
\hline 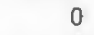 & 110255.12 & 110255.12 \\
\hline 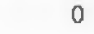 & 110255.12 & 110255.12 \\
\hline
\end{tabular}

O quadro 3 refere-se à distribuição de freqüência da posição do investidor no último dia do mês, correspondente às 72 simulaçōes realizadas, onde foi sempre suposta a cotação inicial de Cr\$ 10,00 .

A política testada apresentou um lucro médio (esperado) de Cr\$33.160,00 para o período de um mês e uma probabilidade de $20,8 \%$ do investidor chegar ao fim do mês com prejuizo.

O simples exame do output da simulação feita sugere uma alternativa melhor que a testada. Verifica-se que se o investidor adotasse como política não vender de modo algum suas ações, teria um lucro esperado, ao fim de um mês, de Cr $\$ 54.800,00$ e a probabilidade de um eventual prejuízo seria de $1,4 \%$.

E claro que a confiabilidade dos resultados obtidos no exemplo exposto depende diretamente da qualidade das previsões relativas às probabilidades do comportamento da ação $\mathbf{A}$.
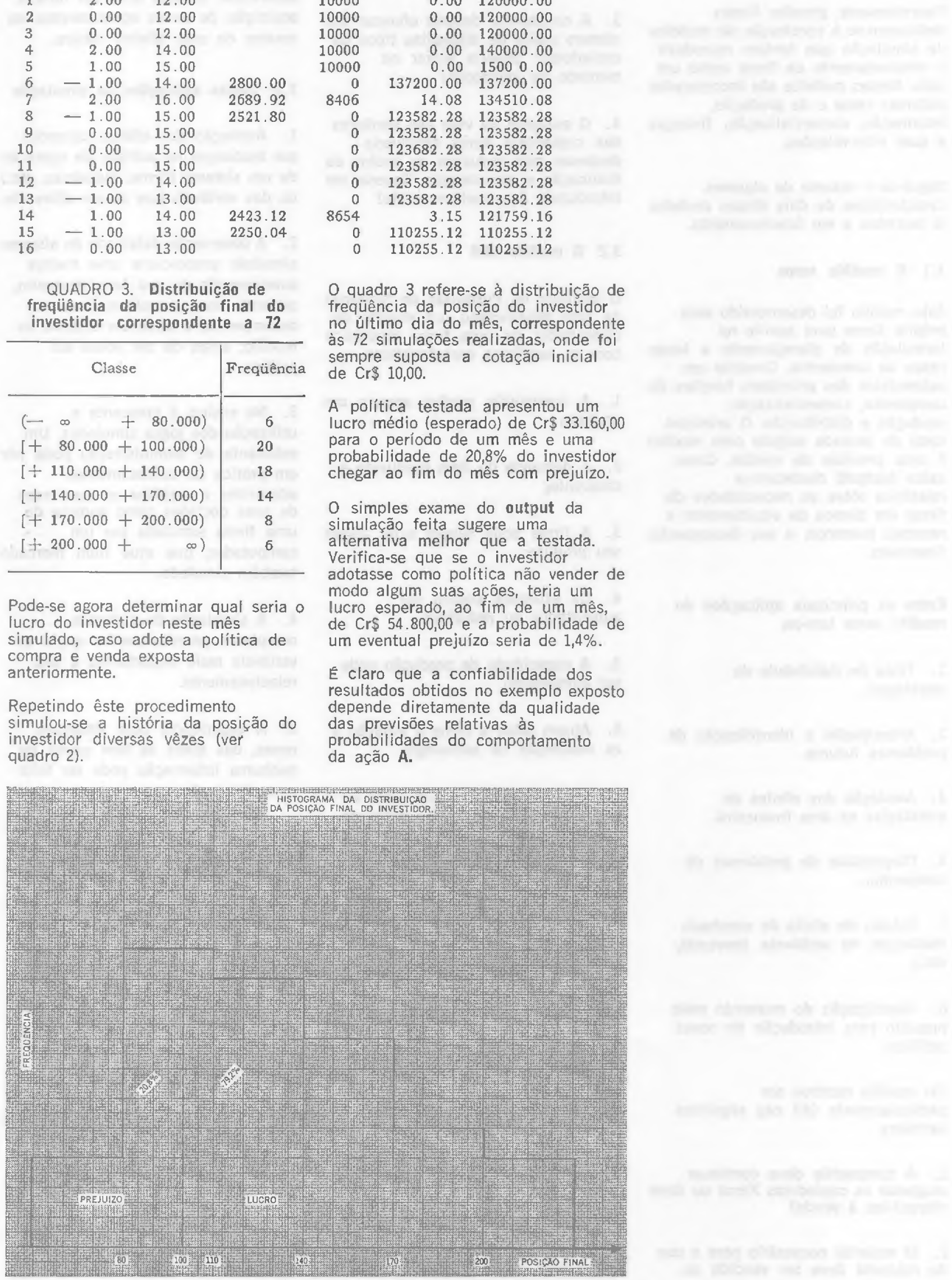


\section{ALGUMAS APLICAÇȮES DA SIMULAÇAO}

Recentemente, grandes firmas dedicaram-se à construção de modelos de simulação que tentam reproduzir o comportamento da firma como um todo. Nestes modelos são incorporados sistemas como o de produção, informação, comercialização, finanças e suas inter-relações.

Segue-se o resumo de algumas caracterísicas de dois dêsses modelos já testados e em funcionamento.

\subsection{0 modêlo xerox}

Este modêlo foi desenvolvido pela própria Xerox para auxílio na formulação do planejamento a longo prazo da companhia. Consiste em submodelos das principais funções da companhia, comercialização, produção e distribuição. O principal dado de entrada exigido pelo modêlo é uma previsão de vendas. Como saida (output) destacam-se relatórios sôbre as necessidades da firma em têrmos de equipamento e recursos humanos, e seu desempenho financeiro.

Entre as principais aplicações do modêlo xerox tem-se:

\section{Teste de viabilidade de} estratégias.

2. Antecipação e identificação de problemas futuros.

3. Avaliação dos efeitos de estratégias na área financeira.

4. Diagnóstico de problemas da companhia.

5. Estudo do efeito de eventuais mudanças no ambiente (mercado, etc.).

6. Investigação do momento mais propício para introdução de novas políticas.

Tal modêlo mostrou ser particularmente útil nas seguintes decisões:

1. A companhia deve continuar alugando as copiadoras Xerox ou deve oferecê-las à venda?

2. O material necessário para o uso da máquina deve ser vendido ou oferecido gratuitamente, isto é, ter seu custo incluido no aluguel?

3. A companhia deveria oferecer um número maior de diferentes tipos de copiadoras? Deveria entrar no mercado de impressão?

4. O aumento da vida dos tambores das copiadoras Xerox envolveria despesas mas reduziria os custos de fabricação e manutenção. Deveria ser introduzido êste melhoramento?

\subsection{0 modêlo IBM}

O Instituto de Pesquisas de Sistemas da IBM desenvolveu um modêlo de computador de uma firma hipotética com as seguintes características:

1. A companhia produz apenas um produto;

\section{A demanda do item produzido é crescente;}

3. A firma pode vender e/ou alugar seu produto;

\section{Os estoques podem ser} aumentados ou reduzidos;

\section{A capacidade de produção pode} ser aumentada;

6. Atuam sôbre a firma a inflação e as mudanças na tecnologia;

7. A expansão de capital pode ser financiada pela venda de ações ou debêntures.

As variáveis de entrada do modêlo incluem preços de aluguel e venda do produto, volume de produção, volume de capital para crescimento da firma, quantidade máxima de capital que pode ser levantado por meio de ações e debêntures.

A saída gerada pelo modêlo, programado para computador do Sistema / 360 consta de balanços da emprêsa, declarações de renda, e relatórios sôbre as fontes e o emprêgo do capital. O programa oferece, assim, meios de avaliação de desempenho da emprêsa.

Variando-se os fatôres de entrada, é possivel comparar as vantagens do aluguel ou da venda dos produtos da companhia, financiamento através de empréstimos ou emissão de ações. É possivel usar o modêlo para determinar quando deve ser feita a aquisição de novos equipamentos ou mesmo de uma fábrica inteira.

\subsection{Outras aplicações da simulação}

1. Avaliação dos efeitos causados por mudanças na política de operação de um sistema (firma, indústrias, etc.) ou das variáveis que atuam sôbre êle.

2. A observação detalhada do sistema simulado proporciona uma melhor compreensão de seu funcionamento, podendo levar a melhoria em seu desempenho; e pode ser testado no modêlo, antes de ser pôsto em prática.

3. No ensino, é crescente a utilização dos jogos simulados. Um estudante de administração pode pôr em prática os conhecimentos adquiridos e verificar os resultados de suas decisões como gerente de uma firma simulada por um computador, que atue num mercado também simulado.

4. A simulação de sistemas complexos permite avaliar quais as variáveis mais importantes e seu relacionamento.

5. A experiência com situações novas, das quais se tem pouca ou nenhuma informação pode ser feita com simulação.

6. Antes de se correr o risco da experiência de novas políticas ou estratégias de decisão no sistema real, pode-se efetuar testes simulados.

7. Em certos tipos de problemas "estocásticos", informações sôbre a média e momento podem ser insuficientes para descrição do sistema. Muitas vêzes, nestes casos, a simulação pode fornecer as informações desejadas.

8. A simulação permite 0 estudo de fenômenos dinâmicos ao longo do tempo.

Os itens citados não são mùtuamente exclusivos e de modo algum esgotam as possibilidades de aplicação da simulação. 